\title{
Observations and modeling of UHF-band scintillation occurrence probability over the low-latitude region of China during the maximum activity of solar cycle 24
}

\author{
H. Zhang ${ }^{1,2}$, Y. Liu ${ }^{2}$, J. Wu ${ }^{2}$, T. Xu ${ }^{2}$, and D. Sheng ${ }^{2}$ \\ ${ }^{1}$ School of Electronic Information, Wuhan University, Wuhan, China \\ ${ }^{2}$ National Key Laboratory of Electromagnetic Environment, China Research Institute of Radiowave Propagation, \\ Qingdao, China
}

Correspondence to: H. Zhang (ssrs_nklee@163.com)

Received: 20 May 2014 - Revised: 1 December 2014 - Accepted: 4 December 2014 - Published: 16 January 2015

\begin{abstract}
The climatological characteristics of UHF-band scintillations over the low-latitude region of China were investigated by analyzing the observations recorded at three stations of our regional network of satellite-beaconbased scintillation monitoring in 2013. The three stations are Hainan (geographic $20.0^{\circ} \mathrm{N}, 110.3^{\circ} \mathrm{E}$; geomagnetic $10.1^{\circ} \mathrm{N}, 177.4^{\circ} \mathrm{W}$, dip $28.2^{\circ}$ ), Guangzhou (geographic $23.0^{\circ} \mathrm{N}, 113.0^{\circ} \mathrm{E}$; geomagnetic $13.1^{\circ} \mathrm{N}, 174.8^{\circ} \mathrm{W}$, dip $33.9^{\circ}$ ) and Kunming (geographic $25.6^{\circ} \mathrm{N}, 103.7^{\circ} \mathrm{E}$; geomagnetic $15.7^{\circ} \mathrm{N}, 176.4^{\circ} \mathrm{E}$, dip $39.0^{\circ}$ ), located at low latitudes of China. The variations of UHF-band scintillation occurrence with latitude, time and season are presented in detail to understand the morphology and climatology of ionospheric scintillations over the low-latitude region of China. An equinoctial asymmetry in the occurrences of scintillation and an obvious difference of the onset time of scintillations between Hainan and Kunming is noted in this data set. Subsequently, the ionosonde data are utilized to study the possible causes of the asymmetry between two equinoxes. The observations suggest that the mean critical frequency $\left(f_{o} \mathrm{~F} 2\right)$ at 20:00 LT (12:00 UT) in the autumnal equinoctial months (September and October) and the vernal equinoctial months (March and April) has a similar asymmetry. The ratio of the mean foF 2 between two equinoxes is proportional to the ratio between the maximum scintillation occurrence in the autumnal equinox and in the vernal equinox. Therefore, this ratio can act as a proxy for the equinoctial asymmetry in the occurrences of scintillation over the low-latitude region of China, and can be used to model the equinoctial asymmetry in our empirical climatological model of scintillation occur-
\end{abstract}

rence probability (CMSOP). The CMSOP can provide the predictions of the occurrences of scintillation over the lowlatitude region of China and was validated in this study.

Keywords. Ionosphere (ionospheric irregularities; modeling and forecasting) - radio science (ionospheric propagation)

\section{Introduction}

Trans-ionospheric radio waves experience a rapid amplitude fading and phase jitter when they pass through electron density irregularities. This phenomenon can be understood as multi-path inside the ionosphere, and this feature is referred to as ionospheric scintillation (Crane, 1977), which varies widely with frequency, time, season, latitude and solar and magnetic activity. The trans-ionospheric signal scintillation causes considerable communication hazards at a wide range of frequencies and is therefore of great practical interest (Banerjee et al., 1992), especially for the users of satellite communication systems, radar and global satellite navigation systems. The study of the climatology of scintillations for understanding and predicting scintillation activity is currently one of the major research topics in the space weather community.

Over the past four decades, many studies on the scintillation theory, observations, morphological and climatological features have been published (e.g., Aarons, 1982, 1993; Yeh and Liu, 1982; Basu and Basu, 1985; Kil and Heelis, 1998; Nishioka et al., 2008; Sripathi et al., 2011). The scintilla- 
tion activities around the anomaly crest are mainly produced by equatorial F-region plasma irregularities, which are commonly referred to as the equatorial spread $\mathrm{F}(\mathrm{ESF}) /$ plasma bubbles. At the magnetic equator around sunset, the $\mathrm{F}$ region can rapidly rise and develop a steep bottom-side density gradient due to the combined effects of recombination of the F1 and E regions and an actual increase in the upward plasma velocity due to pre-reversal enhancement of an eastward electric field (PRE). This results in an unstable F-region plasma density profile, which is considered to be the Rayleigh-Taylor (R-T) instability (Ossakow, 1981). The $\mathrm{R}-\mathrm{T}$ instability results in the generation of plasma bubbles, which move upward and sometimes reach an altitude greater than $1500 \mathrm{~km}$ above the magnetic equator. As the fieldaligned plasma bubbles rise in the equatorial ionosphere, the low-latitude extremities of the bubbles propagate away from the equator in such a way that upper height limit defines the latitudinal extent of the bubbles (Abdu et al., 1983).

The occurrence characteristics of plasma bubbles were studied using ground-based GPS receiver networks; the asymmetry between two solstices and the asymmetry between two equinoxes were found by Nishioka et al. (2008). There were obvious differences in the climatological variations of plasma bubbles occurrence with season and longitude reported by Retterer and Gentile (2009). The morphological and climatological characteristics of VHF-, UHFand $\mathrm{L}$ band scintillations recorded at one station or multiple stations have been extensively presented by Indian researchers (Rama Rao et al., 2005, 2006a, b; Sekar et al., 2007; Sekar and Chakrabarty, 2008; Prasad et al., 2012; Chakraborty et al., 2012; Chatterjee and Chakraborty, 2013). The climatological characteristics of ESF irregularities over the Indian region showed an equinoctial asymmetry in the occurrence of scintillations wherein the occurrence of scintillations was greater in the vernal equinox than in the autumnal equinox (Sripathi et al., 2011). The conspicuous differences in the onset time and duration of VHF scintillations at three stations situated at and around the equatorial ionization anomaly (EIA) crest of the Indian longitude sector were presented by Chatterjee and Chakraborty (2013). Several physical mechanisms have been proposed to explain the seasonal-longitudinal variation. Tsunoda (1985) showed that the occurrence of plasma bubbles reaches the maximum value when the sunsets in the conjugate E regions are simultaneous. Simultaneous sunsets are expected to intensify the PRE. The angle between the geomagnetic declination and the sunset terminator line was introduced as a proxy for the simultaneous sunsets in the conjugate points (Burke et al., 2004). The seasonal-longitudinal variations of plasma bubbles can be determined by the plasma density in the nighttime F region (Kil et al., 2004), and may be closely related to the seasonal-longitudinal variations of the PRE (Li et al., 2007).

The climatological characteristics of UHF-band scintillations over the low-latitude region of China were studied for the first time by analyzing the observations of UHF-band ionospheric scintillations from the three stations to understand the variations of UHF-band scintillation occurrence with latitude, time and season. The possible causes of existing differences, especially the asymmetry between two equinoxes, were explored based on the observations from the three stations located in and far away from the EIA crest of China. A proxy for the asymmetry between two equinoxes is presented which has never been reported before. These results help us develop the climatological model of scintillation occurrence probability (CMSOP) for the low-latitude region of China based on the modeling method of the WideBand MODel (WBMOD) (Secan et al., 1995). The CMSOP can provide predictions of the scintillation occurrence probability, including the variation of the asymmetry between two equinoxes, and thus some predictions of the CMSOP were validated.

\section{Data and method of analysis}

The amplitude scintillations data of the $380 \mathrm{MHz}$ signals from a geostationary satellite (geographic longitude: $100^{\circ} \mathrm{E}$ ) were recorded with our regional network of satellitebeacon-based scintillation monitoring in 2013. The experiments were carried out at three low-latitude stations located at the northern EIA region, which are Hainan (HN), Guangzhou (GZ) and Kunming (KM). The corresponding ionosphere pierce points of $350 \mathrm{~km}$ are (geographic $18.7^{\circ} \mathrm{N}$, $109.6^{\circ} \mathrm{E}$; geomagnetic $8.8^{\circ} \mathrm{N}, 178.0^{\circ} \mathrm{W}$, dip $25.6^{\circ}$ ), (geographic $21.6^{\circ} \mathrm{N}, 112.2^{\circ} \mathrm{E}$; geomagnetic $11.7^{\circ} \mathrm{N}, 175.6^{\circ} \mathrm{W}$, $\operatorname{dip} 31.3^{\circ}$ ) and (geographic $23.8^{\circ} \mathrm{N}, 103.4^{\circ} \mathrm{E}$; geomagnetic $14.1^{\circ} \mathrm{N}, 176.1^{\circ} \mathrm{E}, \operatorname{dip} 35.7^{\circ}$ ), respectively. The intensity data of the $380 \mathrm{MHz}$ signals are recorded at a sampling rate of $20 \mathrm{~Hz}$, and then processed to obtain the raw S4 index at $60 \mathrm{~s}$ intervals, which are edited for spike removal later. A colocated ionosonde is also in operation during the same period, and the ionograms are recorded at $15 \mathrm{~min}$ intervals.

A careful study of the scintillation events in terms of the S4 index and their association with range-/frequency-type spread F on ionograms is carried out through manual ionogram scaling. The percentage occurrence of scintillations is calculated using two methods. The first method is to bin S4 data into half-hour bins based on the hours past the F2region sunset (defined by a local zenith angle of $107^{\circ}$ at the latitude/longitude of the ionospheric penetration point of $350 \mathrm{~km}$ ) over a 1-month interval, and then calculate the percentage of time that S4 index exceeds the threshold (e.g., $\mathrm{S} 4>0.5$ ) in each of these half-hour blocks (Cervera et al., 2001). The second method is to bin S4 data into half-hour bins from 19:00 LT (LT (China standard time) $=\mathrm{UT}+8.0 \mathrm{~h}$ ) over a 1-month interval and then calculate as with the first method. 

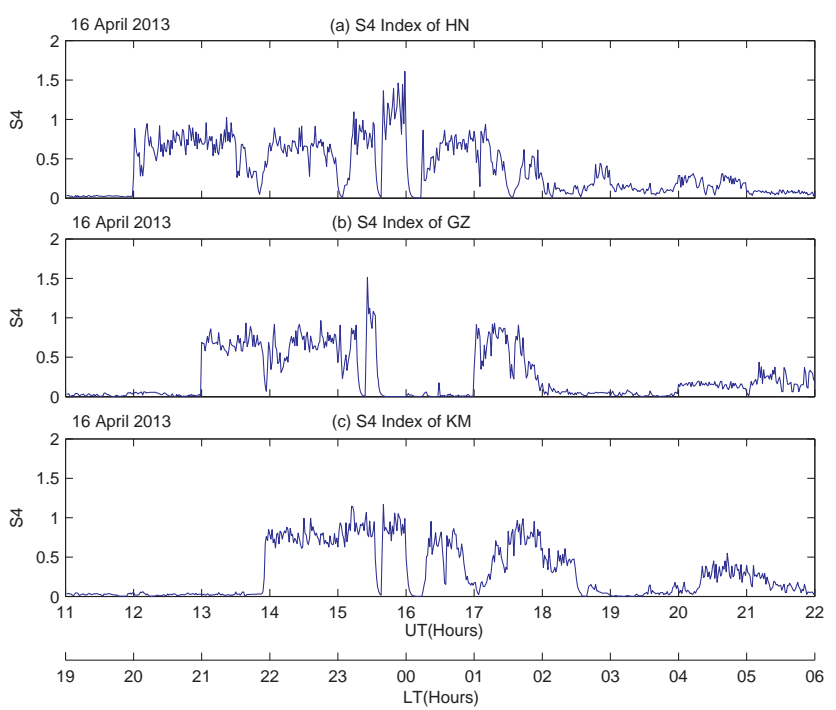

Figure 1. The temporal variations of $S 4$ index of the scintillation events recorded at HN, GZ and KM on 16 April 2013. The local time is China standard time.

\section{Observations}

\subsection{General characteristics of UHF-band scintillation events}

The observations show that the feature of most scintillation events pre-midnight is the abrupt change of S4 index at the onset and end of the events and small variation of S4 index during the events. Those variations of the S4 index are associated with equatorial plasma bubbles (Chatterjee and Chakraborty, 2013). The S4 index often increases rapidly at the onset time of scintillation events and decreases slowly at the end post-midnight. These scintillation events are mainly associated with the remnants of pre-midnight irregularities in their descending and decay phase. It is also reported that some post-midnight irregularities may be associated with the middle-latitude spread-F, which could be triggered by medium-scale traveling ionospheric disturbances (Yokoyama et al., 2011). The scintillation events on the night of 16 April 2013 at the three stations are presented in Fig. 1a$\mathrm{c}$ as typical cases. It is suggested that a series of equatorial plasma bubbles can be continuously generated near the sunset terminator during that night. One plasma bubble can be generated at equatorial latitude in $\mathrm{HN}$ longitude just after sunset; afterward it was mapped in the $\mathrm{F}$ region at $\mathrm{HN}$ latitude, then traversing eastward over GZ. The scintillation events observed at KM may be caused by the passage of the post-sunset plasma bubbles generated westward of KM, and then drifted eastward over KM. It is seen that the first scintillation event recorded at $\mathrm{HN}$ started at 20:00 LT and ended quite abruptly at 00:00 LT, lasting $4 \mathrm{~h}$. And then, the second scintillation event, lasting about $2 \mathrm{~h}$, started abruptly at 00:15 LT and died off quite slowly until 02:00 LT. Simulta-
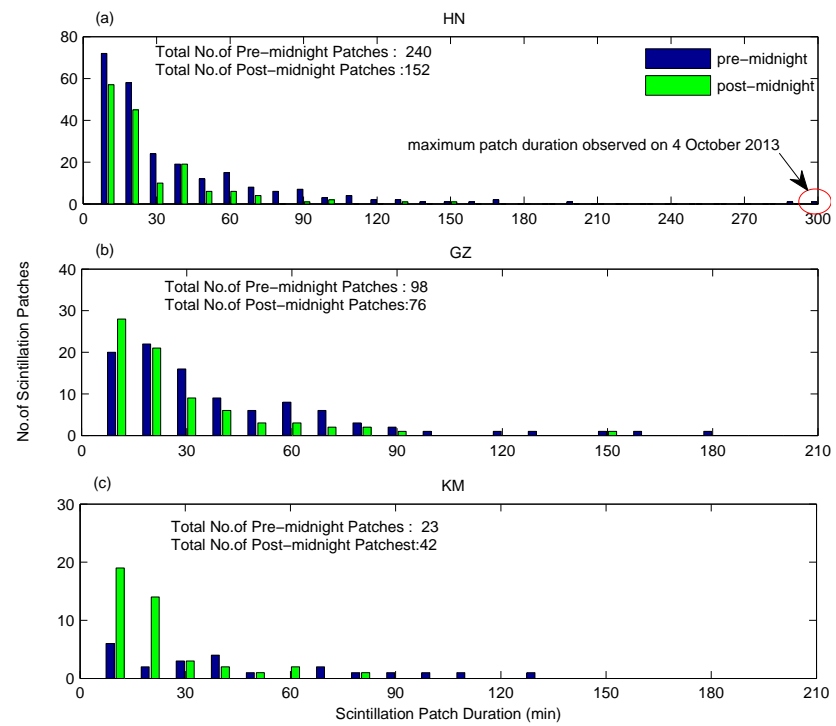

Figure 2. The distributions of the scintillation patch durations for every $10 \mathrm{~min}$ interval observed at the three locations in 2013 . The total number of the scintillation patches is indicated in each of the panels.

neously, the ionograms showed the occurrence of range-type spread-F pre-midnight and frequency-type spread-F postmidnight. The scintillation events of GZ and KM had the similar phenomenon.

\subsection{Scintillation patch durations}

The distributions of scintillation patch durations for every $10 \mathrm{~min}$ intervals are calculated for pre-midnight and post-midnight, respectively, and the results are presented in Fig. 2a-c. The total number of the pre-midnight patches and the post-midnight patches is also indicated in each panel. It is shown in Fig. 2a-c that more than 68, 67 and $72 \%$ of the total number of scintillation patches at HN, GZ and KM, respectively, are of durations less than $30 \mathrm{~min}$, and the maximum patch duration observed at $\mathrm{HN}$ is up to $299 \mathrm{~min}$, which occurred on 4 October 2013. It is clearly evident that the number of the post-midnight patches is fewer compared to that of the pre-midnight patches at $\mathrm{HN}$ and GZ, but it is the very opposite at KM. It should be pointed out that 45 out of 65 scintillation patches at KM occur before 01:00 LT, and most of the scintillation patches occur in the midnight period (22:00-01:00 LT).

\subsection{Nocturnal, seasonal and latitudinal variations of scintillation occurrences}

The nocturnal and seasonal variations in the percentage occurrences of scintillation are calculated using the first method under the condition of $\mathrm{S} 4>0.5$ and are grouped into four seasons: vernal equinox (March, April), summer (May, June, July, August), autumnal equinox (September, October) and 
winter (January, February, November, December). The results are shown in Fig. 3a-d. The percentage occurrences of scintillation at HN, GZ and KM are shown with red dots, blue squares and black triangles, respectively. The five-point smoothed data are shown with lines of corresponding colors. It can be seen from Fig. 3a-d that the maximum percentage occurrence of scintillation occurs during vernal equinox and the minimum occurs in winter. The maximum percentage occurrence of scintillation in the vernal equinox at $\mathrm{HN}$, GZ and KM are 33.2, 22.4 and $10.9 \%$, respectively. Furthermore, it is found that the scintillations mostly occur within 8 , 8 and $6 \mathrm{~h}$ past the F2-region sunset during equinoxes, summer and winter at the three stations, respectively. Hence, we concluded that the occurrence of scintillations is maximal during equinoxes followed by summer, and least in winter over the low-latitude region of China during the high solar activity year of 2013 with the annual mean sunspot numbers $(\mathrm{Rz})$ of 97. This result is consistent with the seasonal behavior in the East Asian-Pacific longitude sector reported by other researchers (e.g., Fang and Liu, 1983; Maruyama and Matuura, 1984; Aarons, 1993; Secan et al., 1995), but different from the observations of the occurrence of scintillations of 2001 and 2002 by some Indian researchers (Rama Rao et al., 2006a; Prasad et al., 2012). Prasad et al. (2012) showed that the occurrence of scintillations was maximal during equinoxes followed by winter, and minimal in summer during the high solar activity years of 2001 and 2002 with Rz varying from 111 to 104 . It is also noted that an equinoctial asymmetry in the percentage occurrences of UHF-band scintillation that the occurrence is greater in the vernal equinox than in the autumnal equinox exists over the low-latitude region of China. The similar equinoctial asymmetries in the occurrences of scintillation over Indonesia (Maruyama et al., 2009) and India (Sripathi et al., 2011) have been reported before. It also can be inferred from the raw observations in Fig. 3a-d that two peak occurrences of scintillation exist in all seasons at HN. The maximum peak occurs pre-midnight and the second peak occurs post-midnight (beyond $4 \mathrm{~h}$ past the F2-region sunset). The two peak occurrences of scintillation also exist during equinoxes and in summer at GZ; nevertheless, the maximum peak in summer occurs after midnight. The possible causes are be discussed below.

\section{Discussion}

\subsection{Asymmetry between two equinoxes}

The observations presented in Fig. 3a-d suggest that the maximum percentage occurrence of UHF-band scintillation occurs during two equinoxes. The observations agree with the theory of Tsunoda (1985) which indicated an important relationship between solar terminator and magnetic field declination for the development of ESF irregularities. The angle between the local geomagnetic meridian and the sunset ter-

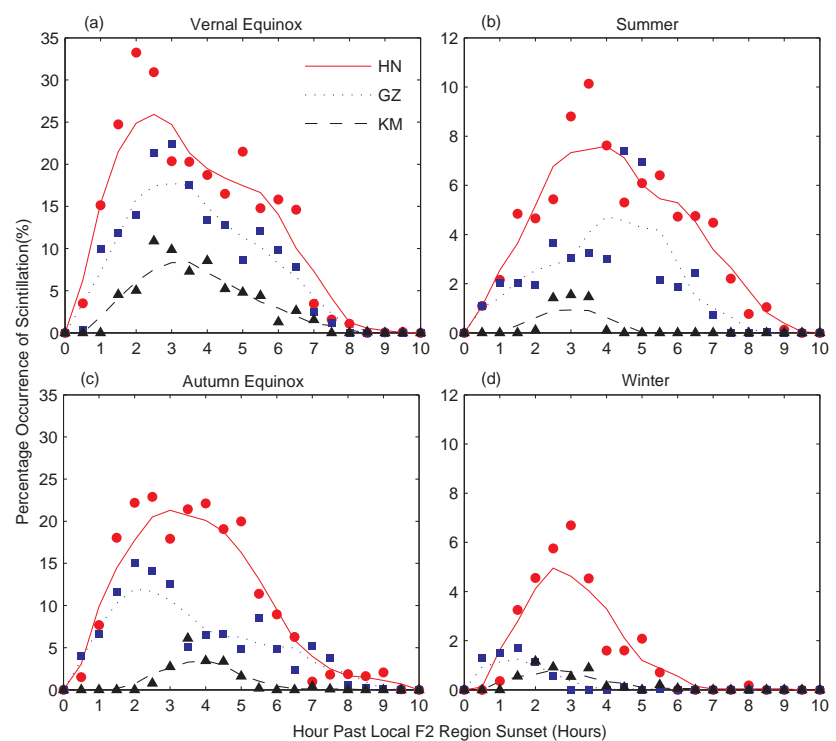

Figure 3. The nocturnal and seasonal variations of the percentage occurrences of scintillation observed at HN, GZ and KM in 2013. The time in the $x$ axis is hours past the F2-region sunset. The time beyond $4 \mathrm{~h}$ past the F2-region sunset belongs to the post-midnight.

minator can act as a proxy for seasonal variation (Secan et al., 1995), which can be used to model the equinoctial symmetric variation.

Figure $3 \mathrm{a}$ and $\mathrm{c}$ also indicate that an equinoctial asymmetry in the percentage occurrences of scintillation exists wherein the occurrence is greater in the vernal equinox than in the autumnal equinox. The equinoctial asymmetry could be caused by the asymmetric distribution of integrated conductivities during equinoctial periods (Nishioka et al., 2008). Meridional wind may be another key factor for the equinoctial asymmetry (Maruyama et al., 2009). Recently, Sripathi et al. (2011) suggested that the height of the irregularity may be different for vernal and autumnal equinox periods, and the background electron density may play a vital role in providing the equinoctial asymmetry in the occurrence of plasma bubbles. In order to understand the mechanism of the equinoctial asymmetry over the low-latitude region of China, we analyzed the monthly mean minimum virtual height $\left(h^{\prime} \mathrm{F}\right)$ and the monthly mean critical frequency $(f o \mathrm{~F} 2)$ of the $\mathrm{F}$ region recorded by ionosondes at $1 \mathrm{~h}$ interval at the three stations. The $h^{\prime} \mathrm{F}$ represents the base of the $\mathrm{F}$ region (F-region omode minimum virtual height) in the nighttime and the base of the F1 region (F1-region o-mode minimum virtual) in the daytime. The $f o \mathrm{~F} 2$ can be used to describe the variation of peak F2-region electron density. Figure $4 \mathrm{a}-\mathrm{c}$ show the temporal variations of the monthly mean $h^{\prime} \mathrm{F}$ over 6 months at the three stations. It can be seen that there is a significant enhancement in the monthly mean $h^{\prime} \mathrm{F}$ during sunset hours in the equinoctial months, which is not found in June (summer) and December (winter). The magnitude of enhancement in 

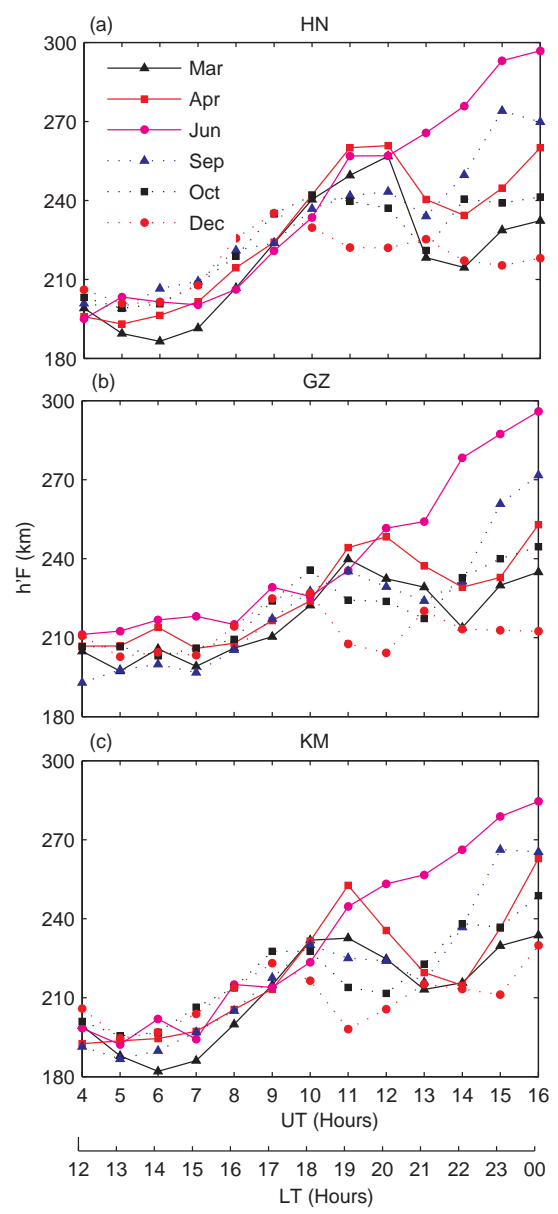

Figure 4. Six months of temporal variations of the monthly mean $h^{\prime} \mathrm{F}$ at the three stations in 2013.

the monthly mean $h^{\prime} \mathrm{F}$ around sunset hours (17:00-20:00 LT) is larger in the vernal equinox than in the autumnal equinox. The basic mechanism of the generation of plasma bubbles is the gravitational $\mathrm{R}-\mathrm{T}$ instability operating on the bottom of the $\mathrm{F}$ region. The growth rate of the instability increases when the height of the F region is high, which causes the decrease of the ion-neutral collision frequency (Maruyama et al., 2009). As a result, the enhancement in the monthly mean $h^{\prime} \mathrm{F}$ during sunset hours indicating the significant uplift of evening $\mathrm{F}$ region may lead to the enhanced scintillations during vernal equinox. Aarons (1982) suggested that the intensity of scintillations depends not only on solar activity but also on the background electron density distribution in the local ionosphere of the respective locations. The enhanced F-region electron density is responsible for the strong ESF activity at most of the longitudes, whereas low plasma density is responsible for suppression of ESF activity. It is supported by our observations in Fig. 5a-c that the monthly mean $f o \mathrm{~F} 2$ around F2-region sunset (about 20:00 LT) in the vernal equinox is higher than in the autumnal equinox. The higher the monthly mean $f o \mathrm{~F} 2$ is, the higher the peak F2-
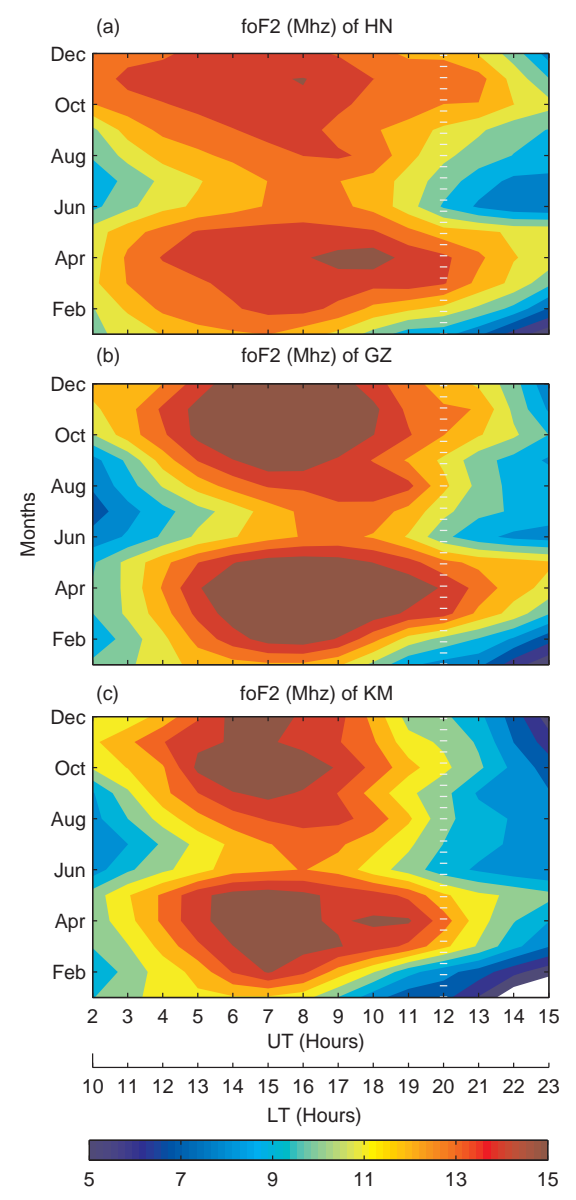

Figure 5. The contours of the monthly mean $f o \mathrm{~F} 2(\mathrm{MHz})$ as a function of time and season at the three stations in 2013. The white dotted line indicates 20:00 LT.

region electron density will be. Thus, the enhanced F-region electron density is a key factor in the difference in the occurrences of scintillation between two equinoxes and may also affect the intensity of scintillations. In particular, it is found that the ratio of the mean $f o \mathrm{~F} 2$ at 20:00 LT in the 2 autumnal equinoctial months to that in the 2 vernal equinoctial months (FATVR) is $0.70,0.65$ and 0.57 at $\mathrm{HN}, \mathrm{GZ}$ and $\mathrm{KM}$, respectively. The FATVR is directly proportional to the ratio of the maximum scintillation occurrence in the autumnal equinox to that in the vernal equinox, which is $0.69,0.67$ and 0.56 at $\mathrm{HN}, \mathrm{GZ}$ and KM, respectively. The results suggest that the background F-region electron density may play an important role in the equinoctial asymmetry, and the FATVR can act as a proxy for the equinoctial asymmetry in the occurrences of scintillation over the low-latitude region of China, which can be used to model the equinoctial asymmetry in the CMSOP.

\subsection{Nocturnal and latitudinal variations}

It can be inferred from the observations presented in Sect. 3 that the latitudinal variations of scintillations observed in 
present study are obvious. The percentage occurrence of scintillations decreases with higher latitude, but the background peak electron density of the $\mathrm{F}$ region is maximal at GZ. Most of the scintillation events at KM occur in the midnight period (22:00-01:00 LT), and the scintillation onsets of $\mathrm{KM}$ lag more than $1 \mathrm{~h}$ past the local F2-region sunset. The irregularities sampled by the scintillation technique from an off-equatorial station are mainly associated with plasma bubbles extending to higher altitudes over the magnetic equator (in this case 650, 909 and $1023 \mathrm{~km}$ for $\mathrm{HN}, \mathrm{GZ}$ and $\mathrm{KM}$, respectively), and then extending down to off-equatorial Fregion altitudes at the sub-ionospheric point for the given geometry. One of the causes of the latitudinal variations may be the solar activity effect on the altitudes where plasma bubbles reach, though it is not understood well (Nishioka et al., 2008). The background peak F-region electron density at GZ is greater than at $\mathrm{HN}$, but the occurrences of scintillation are reversed. It is concluded that the maximum occurrence of scintillation occurs in the southern edge of northern EIA crest over the Chinese region in 2013, which is consistent with the results reported by Rama Rao et al. (2006a). The causes may be associated with the oblique observation geometry. The depth of scintillation, i.e., the amplitude of signal fluctuations, is directly related to the level of fluctuations in the electron density or the integrated electron density deviation $\int \Delta N_{\mathrm{e}} \mathrm{d} l$ along the ray path, where $\Delta N_{\mathrm{e}}$ is the local electron density perturbation. It is controlled by the irregularity amplitude $\Delta N_{\mathrm{e}} / N_{\mathrm{e}}$, the background electron density $\left(N_{\mathrm{e}}\right)$ and its distribution in the ionosphere (Chakraborty et al., 2012). The satellite-to-Earth link suffers from plasma depletion. The link passing through the southern edge of the northern EIA crest may suffer from a greater electron density perturbation than in the northern edge.

Concerning the observations of KM, Huang et al. (2012) reported that most of equatorial plasma bubbles during high solar activity are generated just after sunset, exist in the evening period (19:00-22:00 LT), traverse eastward, become much less depleted and narrower in the midnight period (22:00-01:00 LT) and then cease around midnight, almost completely disappearing after 01:00 LT. The plasma bubbles move upward in the developing phase and downward in the decay phase; therefore, most of plasma bubbles can continuously extend to higher altitudes and reach the highest altitudes in the midnight period. The plasma bubbles can be detected at KM when they reach the altitudes beyond $1000 \mathrm{~km}$ above the magnetic equator, which causes fewer scintillation events and shorter durations. The difference of the onset time of scintillations pre-midnight between KM and $\mathrm{HN}$ may be attributed to the lower vertical rise velocity of the plasma bubbles with higher altitude over the magnetic equator (Chatterjee and Chakraborty, 2013). The above mechanism is proposed to explain the observations of KM. After all the scintillation events are examined manually, it is suggested that the maximum occurrence of scintillation occurring in the postmidnight of the summer at GZ may be caused by the contin-
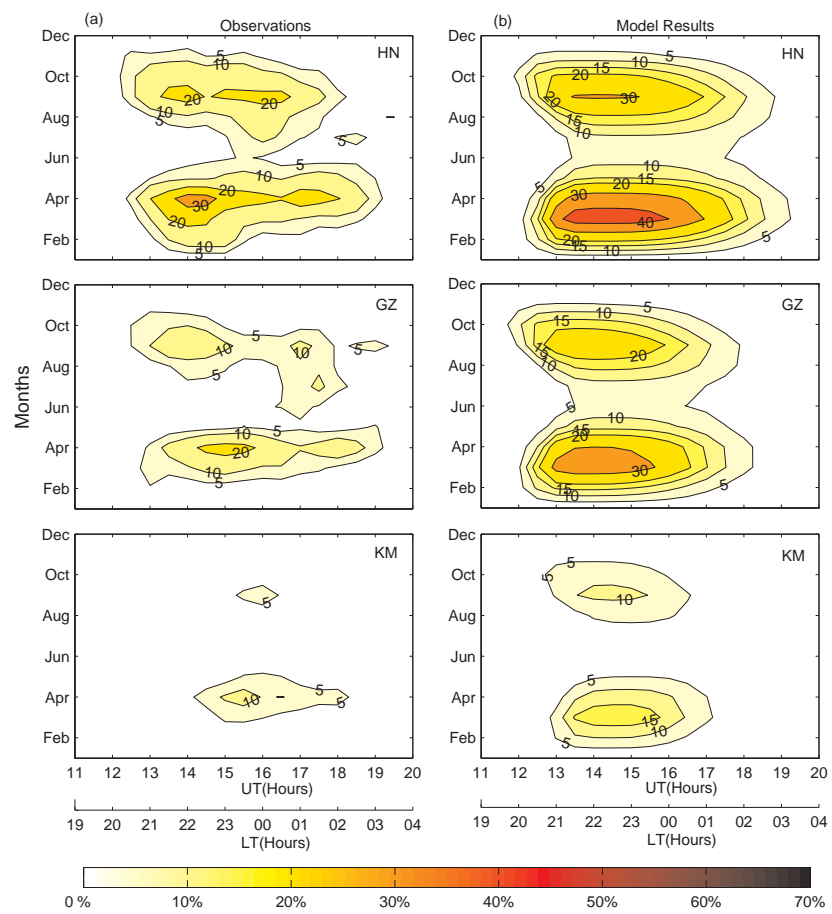

Figure 6. The contours of the percentage occurrences of scintillation calculated using the second method under the condition of $\mathrm{S} 4>0.5$ as a function of time and season are shown for (a) the observations and (b) the predictions of the CMSOP at the three stations for 2013.

uation of the post-sunset equatorial F-region irregularities or the irregularities freshly generated at post-midnight ( $\mathrm{Li}$ et al., 2011).

\subsection{Comparison of observations with predictions of CMSOP}

The CMSOP has been developed to predict the scintillation occurrences over the low-latitude region of China of recent years. As an empirical climatological model, a collection of empirically derived models are used to provide the variations of the full probability distribution function of the irregularity strength parameter $\left(\log \left(C_{k} L\right)\right)$ over the low-latitude region of China. The S4 index of amplitude scintillations for a user-defined system and application scenarios is calculated using a power law phase screen propagation model (Rino, 1979). The CMSOP takes into account the temporal, seasonal, equinoctial asymmetric, latitudinal and longitudinal variations of the occurrences of scintillation as well as the effects of the solar activity and geomagnetic activity. The occurrences of scintillation in the future could be predicted by specifying environment conditions (date, time, monthly mean $\mathrm{Rz}, 3 \mathrm{~h} \mathrm{Kp}$ index at sunset and FATVR) and system parameters (receiver location, transmitter location and frequency). Some predictions of the CMSOP are compared with the observations of the scintillation occurrences at the three 
stations in 2013 for validation. Figure 6a-b show the contours of the percentage occurrences of scintillation calculated using the second method under the condition of S4 $>0.5$ as a function of time and season for the three stations. The left panels are the observations of the percentage occurrences of scintillation smoothed by a $3 \times 3$ median filter. The right panels are the predictions of the CMSOP. It is shown that the predictions of the CMSOP agree in general with the observations, and the asymmetry between two equinoxes is presented. However, there are some differences. The maximum month of the scintillation occurrences in the vernal equinox differs with the observations to a degree, but the maximum month of the scintillation occurrences in the autumnal equinox agrees well with the observations. It is inferred that the relationship between the scintillation occurrence maxima and the sunset nodes is not exact. Slight displacements in the scintillation occurrence maxima from the nodes have been found, and the vernal equinoctial displacement is not necessarily similar to the autumnal equinoctial displacement; this discrepancy indicates that other irregularity-influencing processes, including the solar activity, are operational, which needs further investigation (Tsunoda, 1985).

\section{Summary and conclusions}

In this study, the observations of UHF-band scintillations recorded at the three low-latitude stations of China in 2013 show that scintillation events are associated with the equatorial irregularities and the remnants of pre-midnight irregularities. The number of post-midnight scintillation patches is fewer compared to that of the pre-midnight patches at $\mathrm{HN}$ and GZ, but it is the very opposite at KM. It is concluded that an equinoctial asymmetry in the percentage occurrences of scintillation exists over the low-latitude region of China. Some of the possible sources of the equinoctial asymmetry are studied and the results suggest that background F-region electron density may play an important role in the equinoctial asymmetry. A proxy for the equinoctial asymmetry in the occurrences of scintillation over the low-latitude region of China, which is the FATVR, is introduced for the first time. The FATVR can be used to model the equinoctial asymmetry in the CMSOP. The maximum occurrence of scintillations occurs in the southern edge of northern EIA crest over Chinese region, which may be due to the distribution characteristics of upper height of the equatorial plasma bubbles.

The predictions of the CMSOP agree in general with the observations at the three stations of China in 2013 and may suggest asymmetry between two equinoxes. In the future, the CMSOP should include more details of the scintillation occurrence characteristics and could become more accurate by injecting the precursor signatures of post-sunset equatorial plasma bubbles, such as the enhancement in $h^{\prime} \mathrm{F}$ around sunset hours, and the post-sunset secondary maximum in total electron content.
Acknowledgements. The authors are thankful to NOAA Space Weather Prediction Center (SWPC) for providing solar activity data. The authors appreciate technical support from Chun Chen and Shuji Sun in understanding the physical mechanism of equatorial plasma bubbles, and Panpan Ban and Haiying Li for their work in writing. The authors thank A. K. Patra and the other referees for their valuable comments that greatly improved the manuscript.

Topical Editor H. Kil thanks three anonymous referees for their help in evaluating the manuscript.

\section{References}

Aarons, J.: Global morphology of ionospheric scintillation, P. IEEE, 70, 360-378, 1982.

Aarons, J.: The longitudinal morphology of equatorial F-layer irregularities relevant to their occurrence, Space Sci. Rev., 63, 209, doi:10.1007/BF00750769, 1993.

Abdu, M. A., de Medeiros, R. T., Sobral, J. H. A., and Bittencourt, J. A.: Spread F plasma bubble vertical rise velocities determined from spaced ionosonde observations, J. Geophys. Res., 88, 9197-9204, doi:10.1029/JA088iA11p09197, 1983.

Banerjee, P. K., Dabas, R. S., and Reddy, B. M. C.: C and L band transionospheric scintillation experiment: some results for applications to satellite radio systems, Radio Sci., 27, 955-969, doi:10.1029/92RS01307, 1992.

Basu, S. and Basu, S.: Equatorial scintillations: Advances since ISEA-6, J. Atmos. Terr. Phys., 47, 753-768, doi:10.1016/00219169(85)90052-2, 1985.

Burke, B. J., Gentile, L. C., Huang, C., Valladares, C. E., and $\mathrm{Su}, \mathrm{S}$. Y.: Longitudinal variability of equatorial plasma bubbles observed by DMSP and ROCSAT-1, J. Geophys. Res., 109, A12301, doi:10.1029/2004JA010583, 2004.

Cervera, M. A., Thomas, R. M., Groves, K. M., Ramli, A. G., and Effendy: Validation of WBMOD in the southeast Asian region, Radio Sci., 36, 1559-1572, doi:10.1029/2000RS002520, 2001.

Chakraborty, S. K., Hajra, R., and DasGupta, A.: Ionospheric scintillation near the anomaly crest in relation to the variability of ambient ionization, Radio Sci., 47, RS2006, doi:10.1029/2011RS004942, 2012.

Chatterjee, S. and Chakraborty, S. K.: Variability of ionospheric scintillation near the equatorial anomaly crest of the Indian zone, Ann. Geophys., 31, 697-711, doi:10.5194/angeo-31-697-2013, 2013.

Crane, R. K.: Ionospheric Scintillation, P. IEEE, 65, 180-199, 1977.

Fang, D. J. and Liu, C. H.: A morphological study of gigahertz equatorial scintillation in the Asian region, Radio Sci., 18, 241-252, doi:10.1029/RS018i002p00241, 1983.

Huang, C. S., de la Beaujardiere, O., Roddy, P. A., Hunton, D. E., Ballenthin, J. O., Hairston, M. R., and Pfaff, R. F.: Large-scale quasiperiodic plasma bubbles: C/NOFS observations and casual mechanism, J. Geophys. Res., 118, 3602-3612, doi:10.1002/jgra.50338, 2012.

Kil, H. and Heelis, R. A.: Global distribution of density irregularities in the equatorial ionosphere, J. Geophys. Res., 103, 407-417, doi:10.1029/97JA02698, 1998.

Kil, H., DeMajistre, R., and Paxton, L. J.: F-region plasma distribution seen from TIMED/GUVI and its relation to the equa- 
torial spread F activity, Geophys. Res. Lett., 31, L05810, doi:10.1029/2003GL018703, 2004.

Li, G., Ning, B., Liu, L., Ren, Z., Lei, J., and Su, S.-Y.: The correlation of longitudinal/seasonal variations of evening equatorial prereversal drift and of plasma bubbles, Ann. Geophys., 25, 25712578, doi:10.5194/angeo-25-2571-2007, 2007.

Li, G., Ning, B., Abdu, M. A., Yue, X., Liu, L., Wan, W., and Hu, L.: On the occurrence of postmidnight equatorial $\mathrm{F}$ region irregularities during the June solstice, J. Geophys. Res., 116, A04318, doi:10.1029/2010JA016056, 2011.

Maruyama, T. and Matuura, N.: Longitudinal variability of annual changes in activity of Equatorial Spread F and plasma bubbles, J. Geophys. Res., 89, 903-912, doi:10.1029/JA089iA12p10903, 1984.

Maruyama, T., Saito, S., Kawamura, M., Nozaki, K., Krall, J., and Huba, J. D.: Equinoctial asymmetry of a low-latitude ionosphere-thermosphere system and equatorial irregularities: evidence for meridional wind control, Ann. Geophys., 27, 20272034, doi:10.5194/angeo-27-2027-2009, 2009.

Nishioka, M., Saito, A., and Tsugawa, T.: Occurrence characteristics of plasma bubble derived from global ground based GPS receiver networks, J. Geophys. Res., 113, A05301, doi:10.1029/2007JA012605, 2008.

Ossakow, S. L.: Spread-F theories: A review, J. Atmos. Terr. Phys., 43, 437-452, doi:10.1016/0021-9169(81)90107-0, 1981.

Prasad, S. N. V. S., Rama Rao, P. V. S., Prasad, D. S. V. V. D., Venkatesh, K., and Niranjan, K.: Morphological studies on ionospheric VHF scintillations over an Indian low latitude station during a solar cycle period (2001-2010), Adv. Space Res., 50, 56-69, doi:10.1016/j.asr.2012.03.020, 2012.

Rama Rao, P. V. S., Tulasi Ram, S., Niranjan, K., Prasad, D. S. V. V. D, Gopi Krishna, S., and Lakshmi, N. K. M.: VHF and L-band scintillation characteristics over an Indian low latitude station, Waltair $\left(17.7^{\circ}, 83.3^{\circ}\right.$ E), Ann. Geophys., 23, 2457-2464, doi:10.5194/angeo-23-2457-2005, 2005.

Rama Rao, P. V. S., Tulasi Ram, S., Gopi Krishna, S., Niranjan, K., and Prasad, D. S. V. V. D.: Morphological characteristics of L-band scintillations and their impact on GPS signals: A quantitative study on the precursors for the occurrence of scintillations, in: Proceedings RTO-MP-IST-056 on Characterizing the Ionosphere, RTO, France, 2006a.
Rama Rao, P. V. S., Tulsi Ram, S., Gopi Krishna, S., Niranjan, K., and Prasad, D. S. V. V. D.: Morphological and spectral characteristics of L-band and VHF scintillations and their impact on transionospheric communications, Earth Planets Space, 58, 895904, 2006b.

Retterer, J. M. and Gentile, L. C.: Modeling the climatology of equatorial plasma bubbles observed by DMSP, Radio Sci., 44, RS0A31, doi:10.1029/2008RS004057, 2009.

Rino, C. L.: A power law phase screen model for ionospheric scintillation 1: weak scatter, Radio Sci., 14, 1135-1145, doi:10.1029/RS014i006p01135, 1979.

Secan, J. A., Bussey, R. M., and Fremouw, E. J.: An improved model of equatorial scintillation, Radio Sci., 30, 607-617, doi:10.1029/94RS03172, 1995.

Sekar, R. and Chakrabarty, D.: Equatorial spread-F research in India: a brief review, Indian J. Radio Space, 37, 7-27, 2008.

Sekar, R., Chakrabarty, D., Sarkhel, S., Patra, A. K., Devasia, C. V., and Kelley, M. C.: Identification of active fossil bubbles based on coordinated VHF radar and airglow measurements, Ann. Geophys., 25, 2099-2102, doi:10.5194/angeo-25-2099-2007, 2007.

Sripathi, S., Kakad, B., and Bhattacharyya, A.: Study of equinoctial asymmetry in the Equatorial Spread F (ESF) irregularities over Indian region using multi-instrument observations in the descending phase of solar cycle 23, J. Geophys. Res., 116, A11302, doi:10.1029/2011JA016625, 2011.

Tsunoda, R.: Control of the seasonal and longitudinal occurrence of equatorial scintillations by the longitudinal gradient in integrated E region Pedersen conductivity, J. Geophys. Res., 90, 447-456, doi:10.1029/JA090iA01p00447, 1985.

Yokoyama, T., Pfaff, R. F., Yamamoto, M., Otsuka, Y., Nishioka, M., and Tsugawa, T.: On postmidnight low-latitude ionospheric irregularities during solar minimum: 1. Equatorial Atmosphere Radar and GPS TEC observations in Indonesia, J. Geophys. Res., 116, A11325, doi:10.1029/2011JA016797, 2011.

Yeh, K. C. and Liu, C. H.: Radio-wave scintillations in the ionosphere, P. IEEE, 70, 324-360, 1982. 